\title{
A study on extruded filament bonding in fused filament fabrication
}

\author{
Ana Elisa Costa \\ IPC/i3N - Institute for Polymers and Composites, Department of Polymer Engineering, University of Minho, Guimarães, Portugal \\ Alexandre Ferreira da Silva \\ CMEMS-UMinho - Center of Electro Mechanical Systems, University of Minho, Guimarães, Portugal, and \\ Olga Sousa Carneiro \\ IPC/i3N - Institute for Polymers and Composites, Department of Polymer Engineering, University of Minho, Guimarães, Portugal
}

\begin{abstract}
Purpose - The performance of parts produced by fused filament fabrication is directly related to the printing conditions and to the rheological phenomena inherent to the process, specifically the bonding between adjacent extruded paths/raster. This paper aims to study the influence of a set of printing conditions and parameters, namely, envelope temperature, extrusion temperature, forced cooling and extrusion rate, on the parts performance.

Design/methodology/approach - The influence of these parameters is evaluated by printing a set of test specimens that are morphologically characterized and mechanically tested. At the morphological level, the external dimensions and the voids content of the printed specimens are evaluated. The bonding quality between adjacent extruded paths is assessed through the mechanical performance of test specimens, subjected to tensile loads. These specimens are printed with all raster oriented at $90^{\circ}$ relative to the tensile axis.

Findings - The best performance, resulting from a compromise between surface quality, dimensional accuracy and mechanical performance, is achieved with a heated printing environment and with no use of forced cooling. In addition, for all the conditions tested, the highest dimensional accuracy is achieved in dimensions defined in the printing plane.

Originality/value - This work provides a relevant result as the majority of the current printers comes without enclosure or misses the heating and envelope temperature control systems, which proved to be one of the most influential process parameter.
\end{abstract}

Keywords Mechanical properties, Fused filament fabrication, Dimensional accuracy, Bonding, Mesostructure

Paper type Research paper

\section{Introduction}

Fused filament fabrication (FFF) 3D printing process is possibly the most popular rapid prototyping manufacturing technique because of the low equipment prices, commercial availability of a large range of non-conventional filament materials (electrically conductive, reinforced, flexible, magnetic, thermochromic, among many others) and huge variety of equipment, including multi-material capability and large printing volumes.

The fast and recent developments led to a greater ambition: the use of this technique for the production of functional prototypes and small series of final parts or products. This new paradigm requires demanding features, such as adequate mechanical performance and dimensional accuracy. However, and because of its intrinsic nature, the FFF process is not capable to take total advantage of the mechanical properties of the raw materials it uses, as the extruded paths (raster), deposited in successive rows and layers, are bonded with no extra pressure, or with a short duration compression during the deposition stage. In

The current issue and full text archive of this journal is available on Emerald Insight at: www.emeraldinsight.com/1355-2546.htm

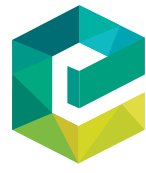

Rapid Prototyping Journal

25/3 (2019) 555-565

(C) Emerald Publishing Limited [ISSN 1355-2546]

[DOI 10.1108/RPJ-03-2018-0062] addition, the temperature of the previously deposited paths decreases during the printing stage and, hence, the thermal conditions for molecular diffusion between them are not the most favorable. In what concerns to the printed parts final dimensions, there is some lack of control, since the extruded material shrinks upon cooling, experiencing different thermo-mechanical conditions. In fact, the temperature of the neighboring zones and the weigh supported by each extruded path vary in space and time along the printing stage. Furthermore, shrinkage cannot be constrained, contrarily to what happens in the majority of the conventional polymer processing technologies.

The polymers used in this technique should present enough melt viscosity to preserve the deposited path shape and printed geometry until solidification. On the other hand, to get a homogeneous part, adhesion and molecular diffusion between neighboring extruded paths is required. These two objectives, dimensional accuracy and mechanical performance, are, therefore, conflicting. Because of the relevance of the topic, the

The authors acknowledge the funding by FCT with the reference projects UID/EEA/04436/2013 and UID/CTM/50025/2013, by FEDER funds through the COMPETE 2020 - Programa Operacional Competitividade e Internacionalização (POCI) with the reference project POCI-01-0145FEDER-006941.

Received 13 March 2018

Revised 11 August 2018

Accepted 11 August 2018 
present work focuses on the effect of the most relevant single material FFF process parameters on the extruded paths bonding, encompassing the analysis of the mesostructure and mechanical performance of printed parts, considering also their final dimensions and appearance.

The paper is organized as follows: after the introduction, a state-of-the-art on bonding is presented in Section 2, helping to better understand this phenomenon and how it depends on several parameters; then, in Section 3, the experimental work performed is described, followed by the discussion of the results in Section 4; finally, the major conclusions are drawn in Section 5.

\section{Bonding}

In the technical literature, several terms have been used to address the cohesion between adjacent extruded paths: sintering, which generally implies the complete fusion of discrete entities; coalescence, which is more adequate when dealing with liquid particles; and bonding, that will be the one used in the context of this work.

In polymer systems, the bonding process requires surface adhesion and molecular diffusion between neighboring deposited paths. This occurs at temperatures above their melting temperature, $T_{m}$, for semi-crystalline materials, or glass transition temperature, $T_{g}$, for amorphous ones (Bellehumeur et al., 1996, 1998; Asgarpour et al., 2011) and involves viscous flow (Bellehumeur et al., 1996; Hornsby and Maxwell, 1992). According to Khaliq et al. (2017), in what concerns to viscous flow, higher polymer melt viscosity leads to poor bonding, since it promotes lower interfacial areas between adjacent extruded paths and also limits molecular diffusion.

In FFF, when the first extruded path is deposited over the heated bed, its temperature is uniform and well above its Tm or $\mathrm{Tg}$, for semi-crystalline or amorphous polymers, respectively. Then, its temperature decreases because of heat transfer, occurring by conduction with the bed and convection and radiation with the surrounding environment, or envelope. When other extruded paths are deposited, new physical contacts between deposited paths are defined, and heat will be also transferred by conduction and radiation between neighboring paths. As a consequence, the thermal history of the interfaces has a crucial role on the quality of the extruded paths bonding (Sun et al., 2003; Li et al., 2002; Bellehumeur et al., 2004; Costa et al., 2017; Seppala et al., 2017). However, the temperature at which neighboring extruded paths of the same layer or of two consecutive layers are bonded varies, making it difficult to predict, as it depends on many variables: envelope temperature, polymer thermal properties, printing conditions, geometry of the part and printing sequence. This evolution of temperature distribution can only be accurately predicted via numerical modeling of the process, as recently done by Zhang et al. (2017). Consequently, the printed parts can be considered as orthotropic composites, constituted by partially bonded paths and voids. This mesostructure has a detrimental effect on the mechanical performance of the part, which is always lower than that of the net polymer employed (Carneiro et al., 2015). To minimize this negative effect, some researchers defined methodologies to determine the optimal part orientation for printing (Umetani and Schmidt, 2013), used copolymers that are cross-linked by radiation, after printing, to enhance the deposited paths bonding (Shaffer et al., 2014), or optimized the design of the printed part to minimize stress concentration (Ahn et al., 2002).

There is a considerable number of works addressing the heat transfer problem in FFF and/or the neck growth (Yardimci and Güçeri, 1996; Sun et al., 2003, 2008; Bellehumeur et al., 2004; Thomas and Rodríguez, 2000; Gurrala and Regalla, 2014; Costa et al., 2017; Zhang et al., 2017), where theoretical models are proposed and, in some cases, experimentally assessed. These studies help to systematize/understand the effect of some variables on bonding, but there is still the lack of a 3D numerical code capable of predicting the temperature and shape of the extruded paths along the printing of complex geometry parts.

In what concerns to experimental studies devoted to the effect of the printing variables on the mechanical performance of FFF printed parts, the majority addresses the raster/ deposited extruded path orientation (see, for example Carneiro et al., 2015; Górski et al., 2015a, 2015b) and the thermal conditions, i.e. extrusion and envelope temperatures Bellehumeur et al., 2004; Gurrala and Regalla, 2014; Spoerk et al., 2017). However, there are few works focused on the effect of other printing parameters, such as the layer (raster) thickness (Wu et al., 2015; Lanzotti et al., 2015; Lee et al., 2005), the raster width (Lee et al., 2005), and the printing velocity (Davis et al., 2017; Seppala et al., 2017).

It is worth mentioning that all the parameters that determine the quality of the deposited extruded paths bonding also affect the mechanical performance of the part. However, this performance is also influenced by other parameters that do not directly affect the bonding quality. To clarify this issue, the fishbone diagram of Figure 1 was built. There, the parameters/factors determining the mechanical performance of the printed parts are grouped by nature and type (direct effect, or no effect, on bonding).

The previously referred works were performed with different materials, used different printing equipment (generally from Stratasys) and analyzed different characteristics of the printed parts. Some are directly related with bonding, but others are devoted to part performance without considering this intermediate level issue. The present work is intended to assess the effect of different parameters on the mesostructure/ extruded paths bonding quality of the printed parts, and on the resulting mechanical performance and dimensional characteristics. The parts are printed with the same material, an ABS filament, and equipment, a modified open-source Prusa i3. The studied parameters related with thermal conditions encompass the envelope temperature, the extrusion temperature, and the convection heat transfer coefficient (through the optional use of forced cooling promoted by a fan located in the extrusion head). Additionally, the effect of the extrusion rate will also be studied. In summary, an open source equipment was used and two new parameters, forced cooling and extrusion rate, were studied, contributing to the completion of the diagram shown in Figure 1.

\section{Experimental work}

\subsection{Material}

The material used is a commercial ABS filament of $1.75 \mathrm{~mm}$ diameter. The density of this material, determined as described 
Figure 1 Parameters affecting extruded paths bonding and part mechanical performance in FFF

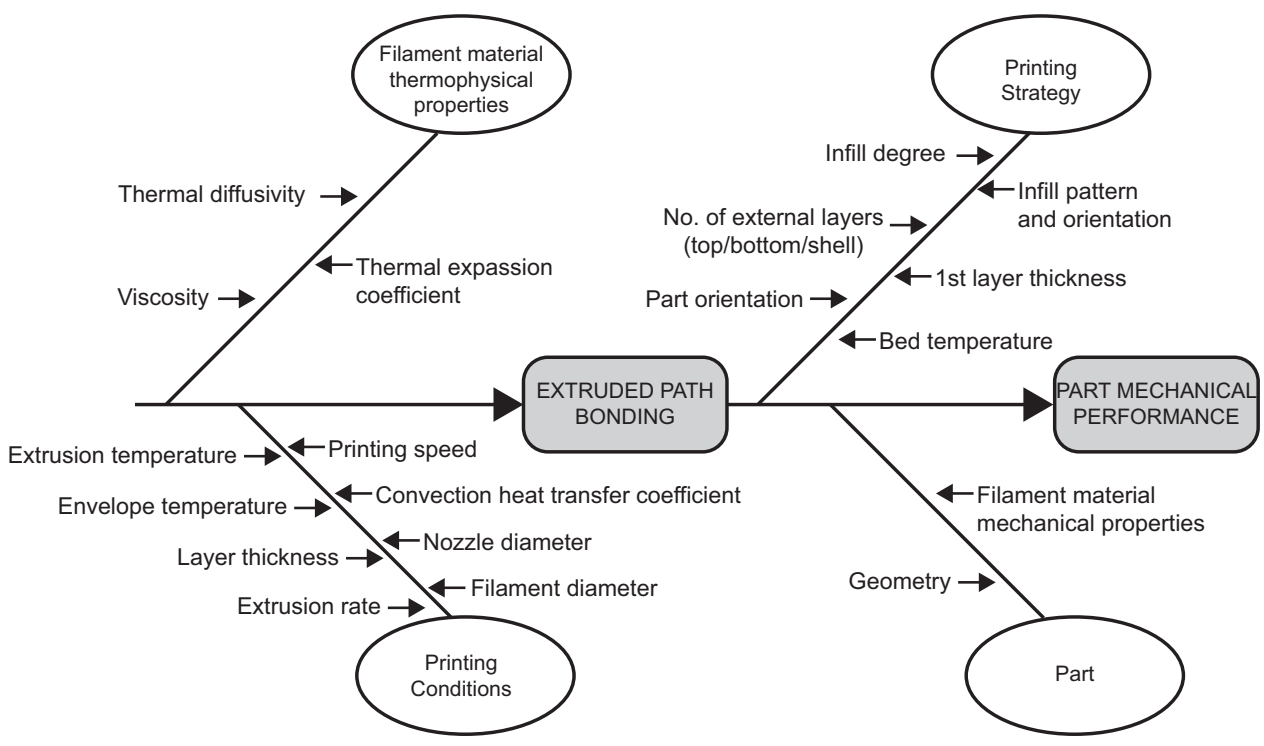

in Section 3.3, is $1.051 \mathrm{~g} / \mathrm{cm}^{3}$. The rheological behavior and $T_{g}$ were previously characterized by the same research group (Khaliq et al., 2017 for details): MFI of $11.2 \mathrm{~g} / 10 \mathrm{~min}$, determined at $230^{\circ} \mathrm{C}$ with a weight of $5 \mathrm{~kg}$, and $T_{g}$ of $107.3^{\circ} \mathrm{C}$. The flow curves, as determined by parallel plate and capillary rheometries, at three different temperatures, are shown in Figure 2 where the effect of shear rate and temperature are well discernible. As can be noticed, the dependence of the viscosity on the temperature is significant, particularly at high shear rates, i.e. within the range occurring during printing. The temperature range of material rheological characterization was limited by its capability to melt during the heating time $\left(220^{\circ} \mathrm{C}\right)$ without apparent degradation $\left(250^{\circ} \mathrm{C}\right)$.

To determine the maximum extrusion temperature, limited by the occurrence of thermal degradation, thermogravimetric analysis, TGA (on a Q500 V6.7 Build 203), and differential scanning calorimetry, DSC (on a Diamond Perkin Elmer), techniques were employed. The TGA test was performed using a temperature sweep from 30 to $800^{\circ} \mathrm{C}$, at a $10^{\circ} \mathrm{C} / \mathrm{min}$ heating rate, in nitrogen atmosphere. In this atmosphere, thermal degradation started around $250^{\circ} \mathrm{C}$, being noticeable around $400^{\circ} \mathrm{C}$ (the mass loss was around 91 per cent in the range 399$471^{\circ} \mathrm{C}$ ). The DSC tests were carried out to determine the oxidation induction time. For this sake, after being heated at 260 and $270^{\circ} \mathrm{C}$ in nitrogen atmosphere, this inert gas was substituted by oxygen. No signs of degradation were detected at these temperatures, despite the information provided by TGA.

\subsection{Printing equipment}

The printing equipment used was a Prusa i3 FFF printer equipped with a BQ Heatcore Unibody extruder. A set of

Figure 2 Shear flow curves of the ABS at different temperatures (data obtained by parallel plate and capillary rheometries)

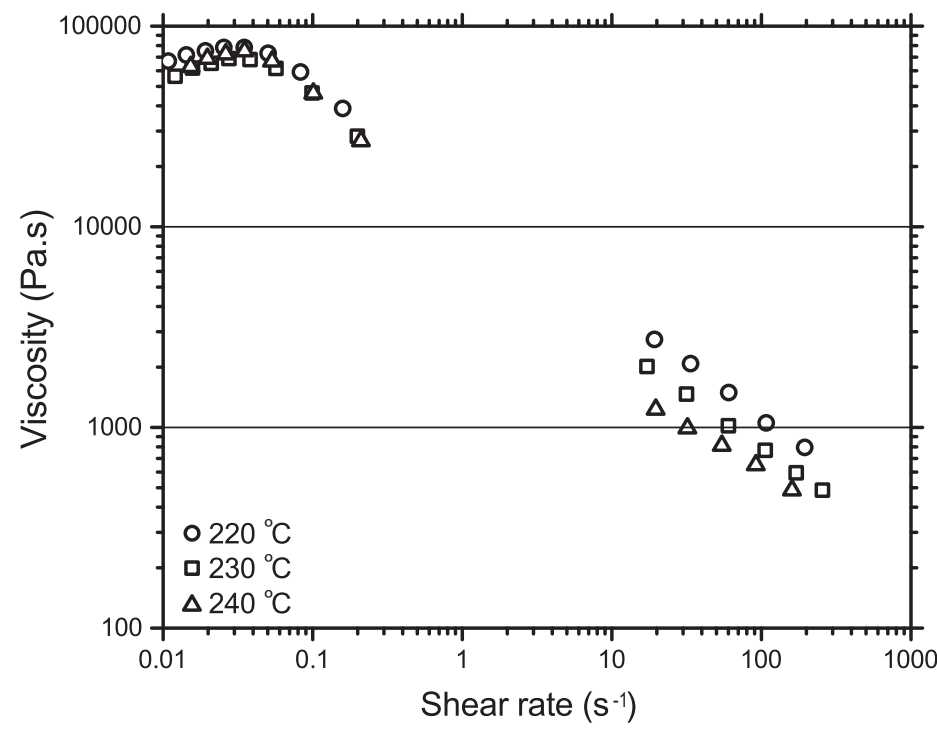


features of this modified printer made it suitable to perform the present study:

- the direct drive extruder compatible with many filament materials, including ABS, featuring a blower at the nozzle exit, which enabled the assessment of using forced cooling right after the extruded path deposition (see detail of the extrusion head in Figure 3);

- the heated bed, which provided a solution to guarantee a good adhesion of the first deposited layer, fixing the part location during the printing stage; and

- the possibility to build an enclosure to evaluate the influence of the envelope temperature.

The in-house designed conditioning enclosure featured a heat source in a close-loop control system based on Arduino that enabled to set the envelope temperature. Because of limitations of the heat source used, the maximum envelope temperature attainable within a reasonable time, one to two hours, was $50^{\circ} \mathrm{C}$. Furthermore, a higher temperature is also not advisable since some of the printer components were made of PLA, which $\mathrm{T}_{\mathrm{g}}$ is around $60^{\circ} \mathrm{C}$.

\subsection{Samples production and characterization}

Tensile test samples according ASTM D790, illustrated in Figure 4, were printed using two different infill angles (Figure 5):

- $90 \%$ for mechanical and mesostructure characterization, in the production of Type-B samples, used in the Bonding study; this orientation was selected to maximize the detrimental effect of poor bonding on the tensile tests (Carneiro et al., 2015; Ahn et al., 2002) and to facilitate the observation of the deposited extruded paths mesostructure; and

- $\pm 45^{\circ}$, the default condition commonly used in FFF, to produce Type-D samples intended for the Dimensional study.

Type-B and Type-D default, or reference, printing conditions are depicted in Table I. The printing parameters as nozzle temperature, bed temperature and layer thickness were determined before the printing of the test samples. Among the community that uses FFF printers as Prusa i3, a recommend calibration protocol available at the RepRap forum and in Coasterman (2011), was followed to determine the optimum printing parameters for the current printer and filament
Figure 4 Normalized tensile samples (all dimensions in $\mathrm{mm}$ ), including the indication of the measurement zones considered in the dimensional analysis

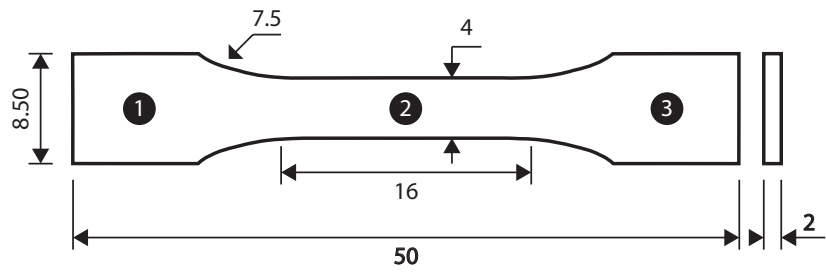

material. The reference extrusion rate for the $90^{\circ} / 90^{\circ}$ infill angle, used in Type-B samples, was not the default one suggested by the slicer ( 100 per cent), which assumes a $-45^{\circ}$ $45^{\circ}$ infill angle. After some printing trials this was adjusted to 150 per cent to guarantee the samples integrity, i.e. contact/ adhesion between two adjacent extruded paths.

To study the effect of the printing parameters, the additional conditions listed in Table II were also considered, both for Type-B and Type-D samples.

The different envelope temperatures used in this work were attained in the following conditions:

- $29^{\circ} \mathrm{C}-$ ambient conditioning enclosure open and heating system off, with the heating coming only from the nozzle;

- $39^{\circ} \mathrm{C}-$ ambient conditioning enclosure closed and heating system off, with the heating coming only from the nozzle; and

- $50^{\circ} \mathrm{C}-$ ambient conditioning enclosure closed and heating system on.

Printing of parts started after reaching the steady state, i.e. when a constant temperature was retrieved by the fixed temperature sensor (Figure 3). The temperature error was evaluated through temperature measurements performed inside the enclosure, at several locations, using a thermocouple. The maximum temperature error was determined for the highest set temperature, being circa $\pm 5^{\circ} \mathrm{C}$. The temperature control system should therefore be further improved, if the objective is to optimize the effect of the envelope temperature. However, it should be mentioned that there are other sources inducing temperature oscillations in the extruded filament, of this order of magnitude, as concluded in the work of Pollard et al. (2017).

Figure 3 Printing equipment used: Prusa i3 FFF printer with an in-house built conditioning enclosure

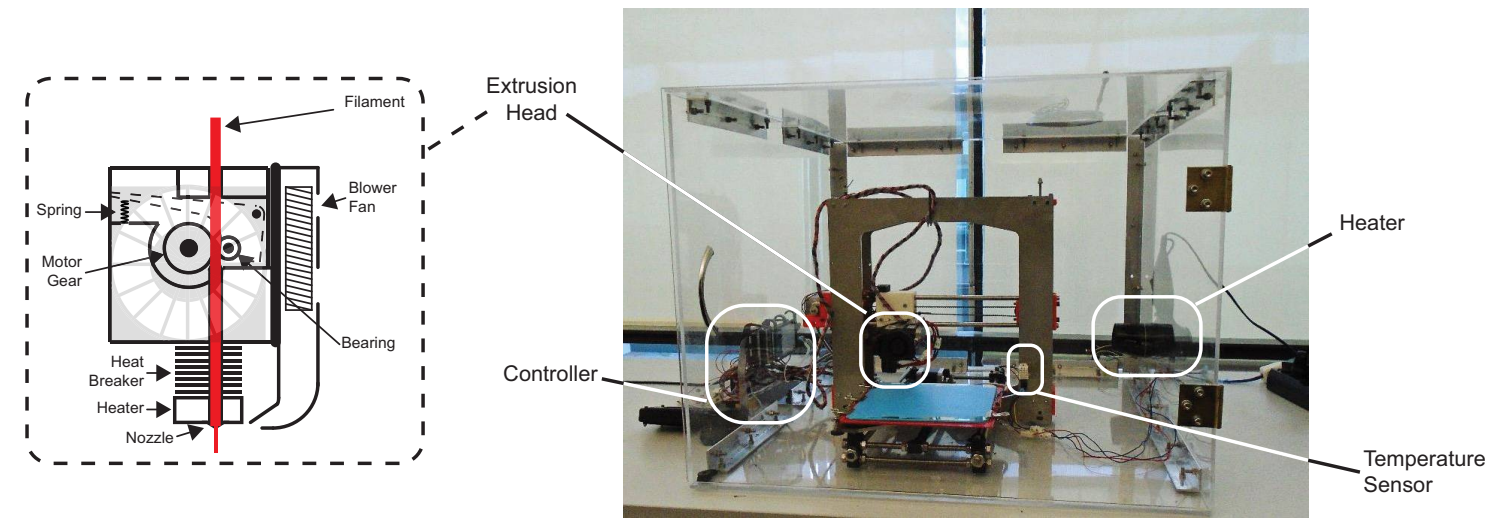


Figure 5 Infill angles used in Type-B and Type-D samples printing

Type-B

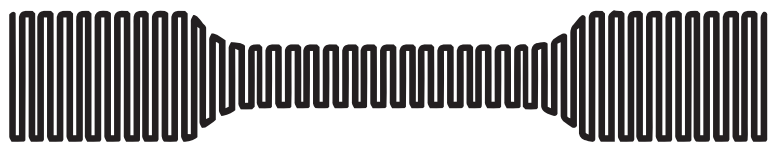

Type-D

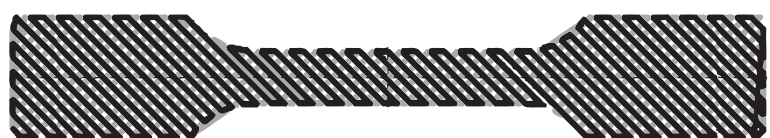

Table I Reference printing conditions used in the production of Type-B and Type-D samples

\begin{tabular}{|c|c|c|}
\hline Parameter & $\begin{array}{c}\text { Type-B } \\
\text { (bonding study) }\end{array}$ & $\begin{array}{c}\text { Type-D } \\
\text { (dimensional study) }\end{array}$ \\
\hline Layer thickness (mm) & & 0.2 \\
\hline Number of perimeters & & 0 \\
\hline $\begin{array}{l}\text { Number of top and bottom } \\
\text { layers }\end{array}$ & & 0 \\
\hline Printing strategy & Linear & Rectilinear \\
\hline Infill degree (\%) & & 100 \\
\hline Raster angle & $90^{\circ} / 90^{\circ}$ & $-45^{\circ} / 45^{\circ}$ \\
\hline Nozzle diameter (mm) & & 0.4 \\
\hline Extrusion rate $(\%)$ & 150 & 100 \\
\hline Extrusion temperature $\left({ }^{\circ} \mathrm{C}\right)$ & & 230 \\
\hline Bed temperature $\left({ }^{\circ} \mathrm{C}\right)$ & & 110 \\
\hline Envelope temperature $\left({ }^{\circ} \mathrm{C}\right)$ & & 39 \\
\hline Forced cooling (YES/NO) & & NO \\
\hline
\end{tabular}

Table II Additional printing conditions used

\begin{tabular}{lc}
\hline Parameter under study & Additional values used \\
\hline Extrusion rate $(\%)$ Type-B & 175,200 \\
Extrusion rate $(\%)$ Type-D & $150,175,200$ \\
Extrusion temperature $\left({ }^{\circ} \mathrm{C}\right)$ & $210,250,270$ \\
Envelope temperature $\left({ }^{\circ} \mathrm{C}\right)$ & 29,50 \\
Forced cooling $(\mathrm{YES} / \mathrm{NO})$ & YES \\
\hline
\end{tabular}

The mesostructure of the printed Type-B samples was characterized using longitudinal microtomed slices of $15 \mu \mathrm{m}$, shown in Figure 6, observed by transmission microscopy (Leica). Having in mind the purpose of this work, the longitudinal direction is the most important one, as it enables to observe extruded paths of different rows and columns (layers). Samples taken in the transversal direction were also observed. However, as they provided little information, they are not shown.

The printed samples voids content was estimated, as a percentage of the volume, from the densities of ABS filament, $\rho_{A B S}$, and of the printed samples, $\rho_{P S}$, assuming that the reduction of density of the printed samples is promoted by the presence of voids (air):

$$
\operatorname{Voids}(\%)=\left(1-\frac{\rho_{P S}}{\rho_{A B S}}\right) 100
$$

Figure 6 Longitudinal cross section of Type-B samples corresponding to the microtomed slices used in microscopic analysis

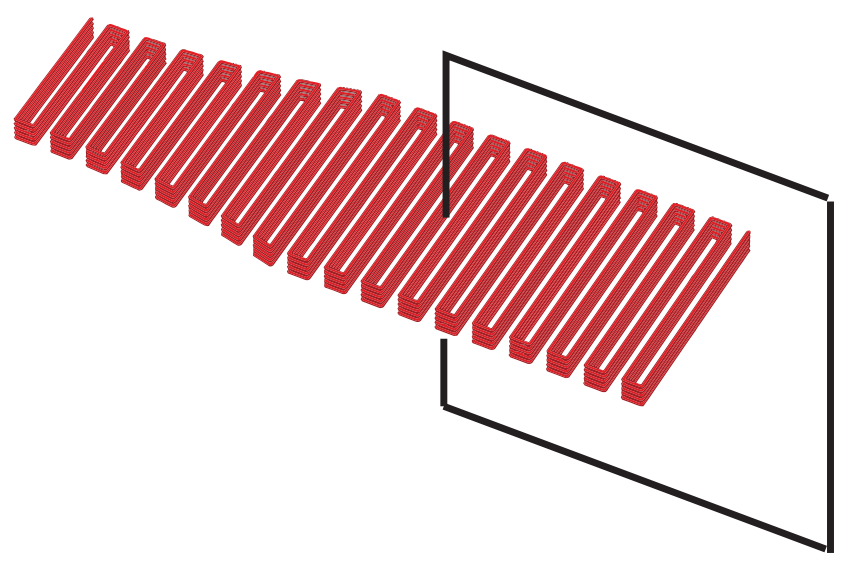

The bulk density of the printed samples was determined by the Archimedes principle. A density determination kit SDK 01 from Scaltec, coupled to a Scaltec SBC 31 weighing scale, was used. Isopropanol, with a density, $\rho_{L}$, of $0.785 \mathrm{~g} / \mathrm{cm}^{3}$, was used to guarantee the total immersion of the samples. For each printing condition five replicas were used to determine the density through the following equation:

$$
\rho_{P S}=\rho_{L} \frac{W}{W-W_{l}}
$$

where $W$ and $W_{l}$ are the weight of the sample measured in air and immersed in the liquid, respectively.

The voids content was also checked based on the longitudinal cross-section micrographs, as a percentage of the cross-section area, via a proper software (Leica Application Suite). For the purpose of this analysis, the top surface of the samples, which is irregular, was not considered, as illustrated in Figure 7.

This last method is not as accurate as the previous since it is based on a single representative section of the samples.

The dimensional and esthetics analyses consisted in the visual observation of Type-D samples surface finishing and in the measurement of their thickness and width in three different zones, depicted in Figure 4. These measurements were performed with a digital caliper that has a $0.01 \mathrm{~mm}$ resolution, adequate to measure desktop FFF printings that have a dimensional tolerance of around $\pm 0.5 \mathrm{~mm}$.

For the mechanical performance assessment, tensile tests were carried out in an INSTRON 4505 universal testing 
Figure 7 Example of the voids detected (as light areas) via the image analysis software

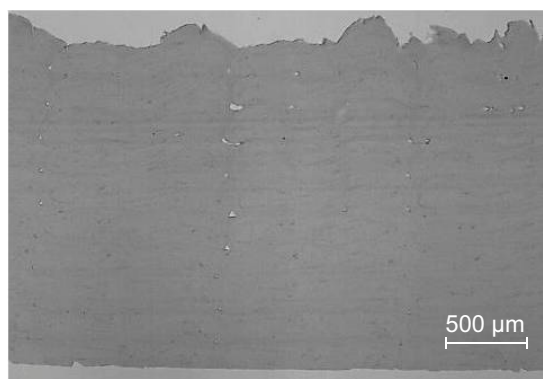

machine at a crosshead speed of $50 \mathrm{~mm} / \mathrm{min}$, typically used for testing thermoplastic samples, and a $20 \mathrm{~mm}$ initial length, using Type-B samples. For each printing condition, five specimens were tested.

\section{Results and discussion}

\subsection{Dimensional/aesthetic analysis (Type-D samples)}

This analysis is done with Type-D samples. Images of typical specimens printed in the reference conditions and in the additional ones are show in Figure 8.

The dimensional data are summarized in Table III where the relative errors of the different dimensions, computed in relation to the corresponding target (drawing) values, are listed. The information relative to the samples printed with different extrusion rates is not included given the inadequacy of these conditions to reproduce the required geometry.

The best general aspect and surface finishing were obtained for the reference condition, for the extrusion temperature of

Figure 8 Examples of Type-D samples printed in different conditions

Reference condition $\left(100 \% ; 230^{\circ} \mathrm{C} ; 39^{\circ} \mathrm{C}\right.$; NO Forced cooling)

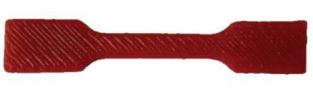

\begin{tabular}{ll}
\hline Extrusion rate (\%) & 150 \\
\hline & 200 \\
\hline Extrusion temperature $\left({ }^{\circ} \mathrm{C}\right)$ & 250 \\
\hline & 270 \\
\hline & 50 \\
\hline & \\
\hline
\end{tabular}

$250^{\circ} \mathrm{C}$, and for all the envelope temperatures used. Therefore, it can be conclude that the higher extrusion temperature used $\left(270^{\circ} \mathrm{C}\right)$, which is above the on-set degradation temperature determined by TGA, originates a worse surface finish/aspect when compared to the remaining $\left(230^{\circ} \mathrm{C}\right.$ and $\left.250^{\circ} \mathrm{C}\right)$. The increase in extrusion rate, in relation to the reference one, has an evident detrimental effect on the aspect, and also on the dimensions of the printed samples. The forced cooling does not contribute to a better appearance.

In relation to the dimensional accuracy, the conclusion is almost the same. From Table III, it is obvious that the minimum errors occur in the reference printing conditions and when an envelope temperature of $50^{\circ} \mathrm{C}$ is used. This last condition is slightly better than the reference one, resulting in precise dimensions in what concerns to width, in all the zones considered, and errors of 12-15 per cent in what concerns to thickness. As a general comment, it can be said that the dimensional errors are much higher in thickness than in width. Despite the perfect match between the target thickness ( $2 \mathrm{~mm})$, and the theoretical printed thickness (10 layers of $0.2 \mathrm{~mm}$ thickness each; Table I), the error in this dimension is always high attaining values, in specific printing conditions, of more than 20 per cent. This results from the fact that the errors are cumulative in the printing direction, which in this case encompasses the samples thickness. On the other hand, the errors are not cumulative in the printing plane, where the width is defined. This puts in evidence the relevance of part orientation, and the need to consider the critical dimensions defined in the printing plane.

Some of the results obtained in this 'dimensional' study will be better understood in the next section, where the Type-B samples structure analysis is performed.

\subsection{Bonding/structure analysis (Type-B samples)}

Examples of micrographs of the longitudinal cross-section of Type-B samples, obtained for all the printing conditions, are presented in Figure 9.

The bulk densities of the samples are shown in Table IV, where the reproducibility of the results is evident. The corresponding estimates of (volumetric) voids content, computed with equation (1), are shown in Figure 10. It should be mentioned that these values are qualitatively in-line with those determined via the micrographs analysis, not shown. However, these last were always lower, putting in evidence the lack of homogeneity of the samples mesostructure.

Considering the information provided by the micrograhs (Figure 9) and the voids contents (Figure 10), a visible effect, 
Table III Type-D samples dimensions (width, w, and thickness, t) relative errors, determined in the zones defined in Figure 4

\begin{tabular}{|c|c|c|c|c|c|c|c|}
\hline & & \multicolumn{6}{|c|}{ Zone } \\
\hline & & \multicolumn{2}{|c|}{1} & \multicolumn{2}{|c|}{2} & \multicolumn{2}{|c|}{3} \\
\hline & & $\mathbf{w}$ & $t$ & w & $t$ & $\mathbf{w}$ & $t$ \\
\hline \multirow{2}{*}{\multicolumn{2}{|c|}{ Target dimension (mm) }} & 8.50 & 2.00 & 4.00 & 2.00 & 8.50 & 2.00 \\
\hline & & \multicolumn{6}{|c|}{ Error (\%) (measured value - target value)/target value } \\
\hline \multicolumn{2}{|c|}{ Reference condition $\left(230^{\circ} \mathrm{C} ; 39^{\circ} \mathrm{C}\right.$; NO Forced cooling) } & 0 & 18 & 2 & 17 & 0 & 18 \\
\hline \multirow[t]{2}{*}{ Extrusion temperature $\left({ }^{\circ} \mathrm{C}\right)$} & 250 & 1 & 20 & 3 & 18 & 3 & 23 \\
\hline & 270 & 4 & 22 & 12 & 18 & 3 & 27 \\
\hline \multirow[t]{2}{*}{ Envelope temperature $\left({ }^{\circ} \mathrm{C}\right)$} & 29 & 3 & 27 & 9 & 21 & 3 & 26 \\
\hline & 50 & 0 & 14 & 0 & 12 & 0 & 15 \\
\hline Forced cooling & Yes & 5 & 17 & 10 & 14 & 4 & 17 \\
\hline
\end{tabular}

Figure 9 Micrographs of longitudinal cross-sections of Type-B samples printed in different conditions
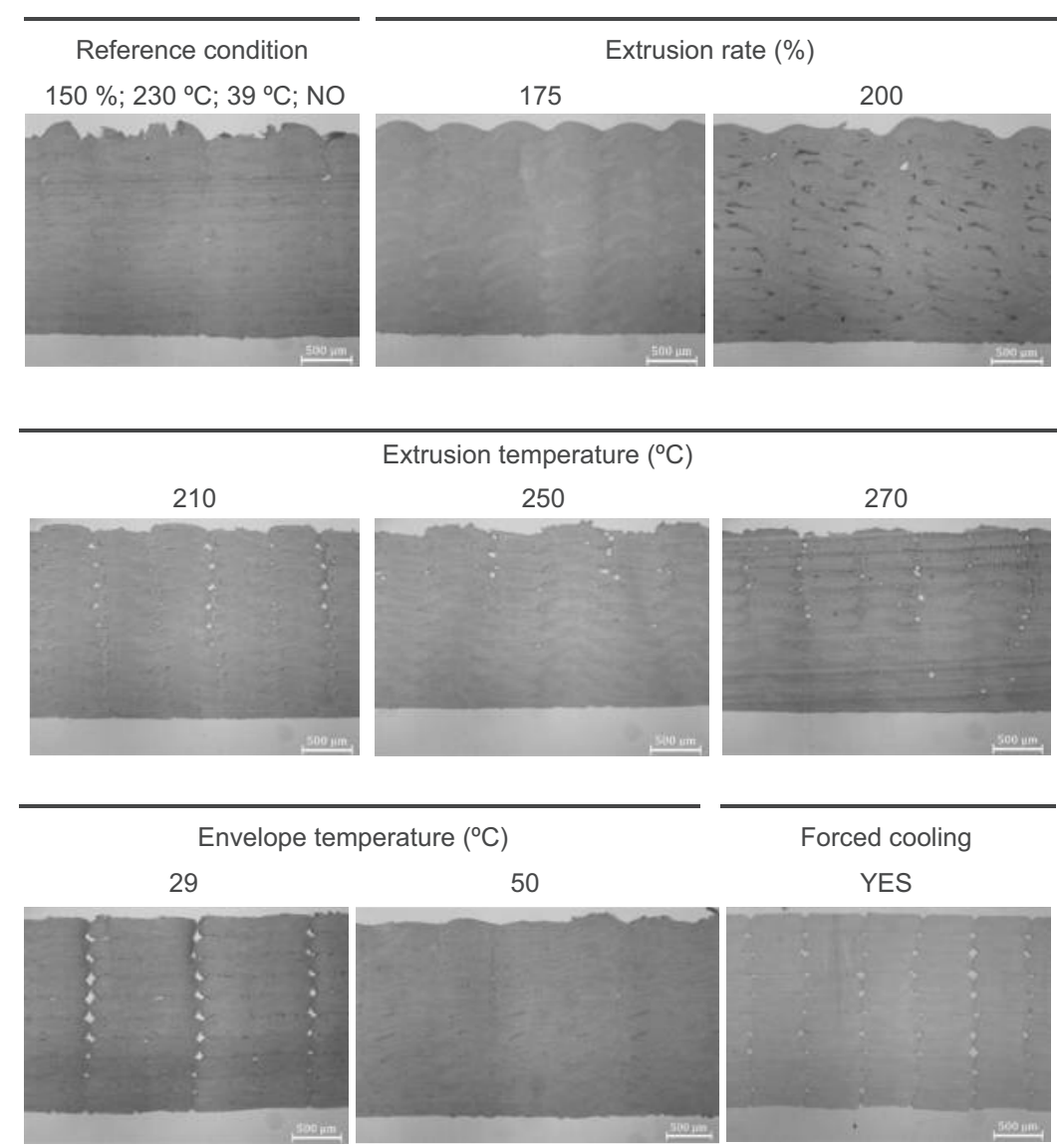

Forced cooling

YES

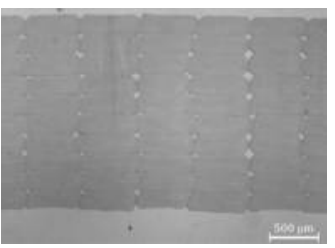

both qualitative and quantitative, of all the printing parameters on the mesostructure of the samples is perceived. At the reference printing condition the printed part is highly compact, showing a low value of voids content, of the order of 1.57 per cent. For the remaining conditions, the following is observed:

- Extrusion rate - higher values of this parameter, relative to the reference one (150 per cent), led to lower values of voids content $(0.73$ and 0.98 per cent for extrusion rates of 175 per cent and 200 per cent, respectively) since more material is extruded. Printing in these conditions results in almost compact structures (see Figure 9), but originates a "wavy" mesostructure, mainly evident for the highest value
(200 per cent), but also apparent for 175 per cent extrusion rate. For the higher extrusion rate (200 per cent), the excess of material is impossible to accommodate in the successive layers, originating waves that result in a slight increase in voids when compared to the 175 per cent case.

- Extrusion temperature - the more compact mesostructures are obtained for the intermediate temperatures, $230^{\circ} \mathrm{C}$ (reference temperature) and $250^{\circ} \mathrm{C}$, with similar values of voids content ( 1.57 and 1.52 per cent, respectively). For a lower value of this parameter $\left(210^{\circ} \mathrm{C}\right)$, the voids content increased from 1.57 to 2.48 per cent. The resulting poor bonding is evident in Figure 9. This is most probably 
Table IV Bulk density of Type-B samples

\begin{tabular}{lccc}
\hline \multirow{2}{*}{ Printing conditions } & \multicolumn{2}{c}{ Density $\left(\mathrm{g} / \mathrm{cm}^{3}\right)$} \\
Average & SD \\
\hline Reference condition & $150 \%, 230{ }^{\circ} \mathrm{C}, 39^{\circ} \mathrm{C}$, & 1.034 & 0.008 \\
& $\mathrm{NO}$ forced cooling & & \\
Feed rate $(\%)$ & 175 & 1.043 & 0.001 \\
& 200 & 1.040 & 0.000 \\
Extrusion & 210 & 1.024 & 0.008 \\
temperature $\left({ }^{\circ} \mathrm{C}\right)$ & 250 & 1.035 & 0.002 \\
& 270 & 1.019 & 0.004 \\
Envelope temperature & 29 & 1.017 & 0.008 \\
$\left({ }^{\circ} \mathrm{C}\right)$ & 50 & 1.034 & 0.003 \\
Forced cooling & $\mathrm{YES}$ & 1.028 & 0.005 \\
\hline
\end{tabular}

because of a decrease in molecular mobility/diffusion corresponding to a higher material viscosity (Figure 2) and to the faster cooling of the extruded paths. The same effect of the extrusion temperature was observed by Spoerk et al. (2017), for PLA. The corresponding micrograph shows that the majority of the individual deposited paths is discernible. The only exceptions are those belonging to the first four layers that show a higher bonding length. This is because of the higher weight they are subjected to, to the beneficial effect of the heat conducted from the heated bed, and from lower heat losses to the environment. For a higher temperature $\left(270^{\circ} \mathrm{C}\right)$, the bonding quality is also worse than the reference one, as can be seen through the micrographs and voids content (2.98 per cent). A plausible justification is some effect promoted by polymer degradation, as indicated by the TGA experiments and rheological characterization.

- Envelope temperature - the best envelope temperatures tested are the highest $\left(50^{\circ} \mathrm{C}\right)$, and the reference one $\left(39^{\circ} \mathrm{C}\right)$, resulting in similar voids content of 1.53 and 1.57 per cent, respectively. The worst is the lower one $\left(29^{\circ} \mathrm{C}\right)$, presenting the higher value of voids content among all the tested conditions (3.23 per cent). This parameter showed to be the most influential one. In fact, a $10^{\circ} \mathrm{C}$ reduction of the envelope temperature, from the reference value of $39^{\circ} \mathrm{C}$ to $29^{\circ} \mathrm{C}$, promotes a significant variation of the voids content from 1.57 to 3.23 per cent. Also, at $29^{\circ} \mathrm{C}$, all the extruded paths are discernible (Figure 9 ). The importance of this parameter comes from the fact that it has a permanent contribution, being effective during all the printing stage, thus maintaining the extruded paths at a specific minimum temperature, i.e. the envelope temperature. The extrusion temperature is not so influent because it has a temporary effect that vanishes with the progressive cooling of the extruded path. This drop in temperature occurs by conduction with the previously extruded paths, and by convection and radiation with the environment (see, for example, Costa et al., 2017).

- Forced cooling - having in mind the previous discussion, the result obtained with the forced cooling is the expected one. The fast cooling of the extruded path promoted by the fan hinders the deformation of adjacent extruded paths and molecular diffusion between them, increasing the voids content from 1.57 per cent (reference condition, with no forced cooling) to 2.16 per cent.

\subsection{Mechanical properties (Type-B samples)}

The mechanical properties of the different samples should relate with their mesostructure. The properties considered were the Young's modulus and the tensile strength, or ultimate strength, shown in Figure 11.

All the samples tested presented a brittle behavior, as expected from its base material (ABS). Having in mind the associated standard deviation values, the influence of the extrusion temperature and the use, or not, of forced cooling seem to have no significant effect on the mechanical performance of the

Figure 10 Voids percentage for each printing condition (Type-B samples), estimated from the samples bulk density values shown in Table IV (the values in bold represent the reference condition)

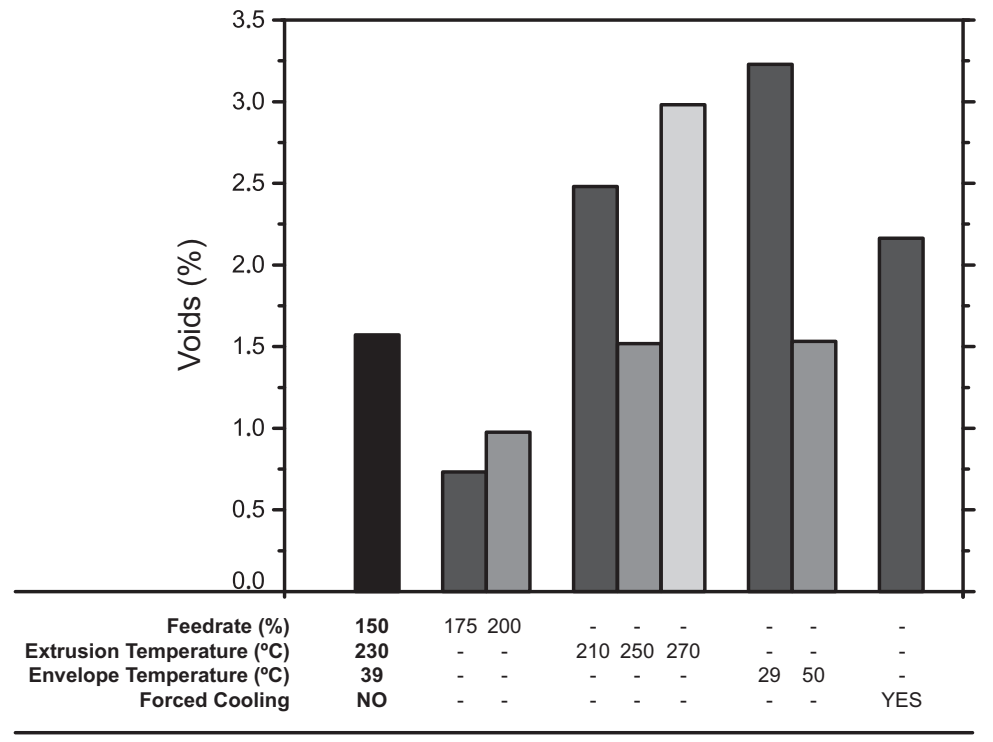


Figure 11 Mechanical properties of Type-B samples: (a) Young's modulus; (b) ultimate strength

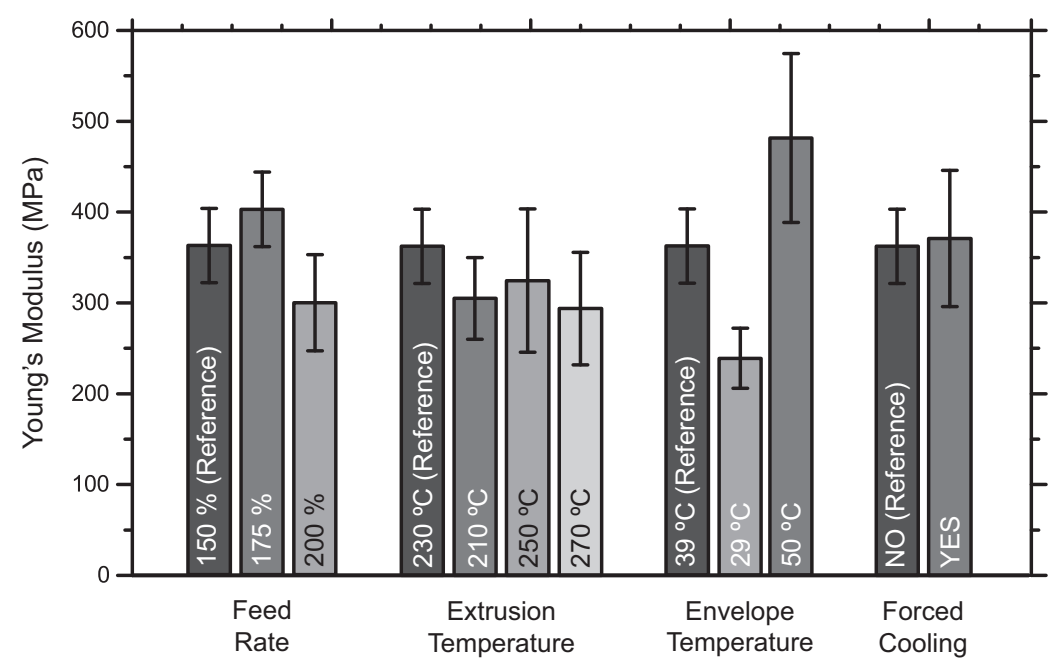

(a)

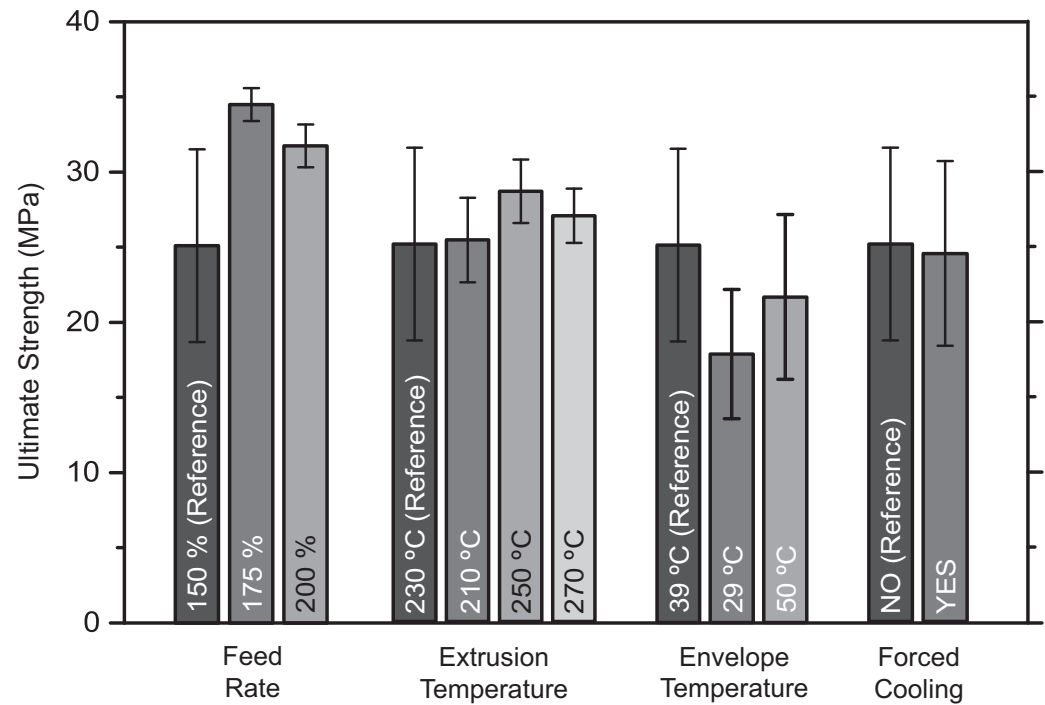

(b)

printed specimens. Therefore, the most influencing parameters are the envelope temperature and the extrusion rate.

The mesostructure and voids content puts in evidence different bonding lengths but do not provide any information concerning the bonding quality of these contact lengths. However, since higher bonding lengths imply higher deformation of the extruded paths until solidification, these should be associated to a lower viscosity of the material. The Young's modulus was determined at very low strains (in the range $0.05-0.25$ per cent), i.e. in the elastic region of the strainstress curves, while the ultimate stress was attained at relatively large strains (in the range of 5-13 per cent), corresponding to the samples rupture. The Young's modulus is essentially dependent on the material while the ultimate stress is also dependent on the structure of the printed samples. Having this in mind, direct effects of molecular diffusion between neighboring extruded paths on the modulus, and of the structure/voids content on the ultimate strength are expected. Therefore, a similar dependence of modulus and ultimate strength on the voids content is also expected. From Figure 11, an overall agreement can be found between the two properties analyzed. Focusing on the Young's modulus [Figure 11(a)], and only on the significant parameters, it can be concluded that the best results are obtained for an envelope temperature of $50^{\circ} \mathrm{C}$, and for the extrusion rate of 175 per cent. These, in turn, are the printing conditions that led to the lower values of voids content ( 1.53 and 0.98 per cent, respectively).

The tensile strength results led to the same conclusion when the extrusion rate is considered. In what concerns to the envelope temperature, the maximum value occurs for the reference condition $\left(39^{\circ} \mathrm{C}\right)$, and not for $50^{\circ} \mathrm{C}$ as the Young's modulus. However, for the set of envelope temperatures tested the dispersion of the results is high, jeopardizing a clear conclusion on the best envelope temperature. 


\section{Conclusions}

In this work, two studies were performed with a view to determine the effect of some of the most influential printing parameters on the surface finishing quality, dimensional accuracy and mechanical performance of printed parts. For this sake, two different types of tensile bar samples were printed. For the dimensional study, Type-D samples were used, produced with a $\pm 45^{\circ}$ infill angle, the most used in FFF technique since it reduces part anisotropy. For the bonding study, Type-B samples were printed with a $90^{\circ} / 90^{\circ}$ infill degree, to facilitate their mesostructure analysis and to maximize the detrimental effect of poor bonding on the tensile tests results. The inclusion of the envelope temperature as a study parameter forced the development and building of an environmental enclosure with controlled temperature.

The set of results provided by the two studies showed that the best dimensional accuracy, surface quality and degree of bonding do not occur for the same printing conditions. Lower temperatures of the extruded paths, resulting from the use of low extrusion and envelope temperatures or from the use of forced convection cooling, originated better surface aspect. However, these are not the most favorable conditions for bonding and, hence, for the mechanical performance or for dimensional accuracy. The same can be said in relation to the extrusion rate. Higher values than the reference one contribute to a higher compactness of the printed samples, resulting in a higher Young's modulus, but originates high dimensional errors and a poor surface finish.

The most influential printing parameter showed to be the envelope temperature, because of its lasting effect.

In conclusion, the overall best printing conditions are those that result in a better compromise of surface quality, dimensional accuracy and mechanical properties. In this study, these conditions are those used as reference: extrusion rate of 150 per cent; extrusion temperature of $230^{\circ} \mathrm{C}$; envelope temperature of $50^{\circ} \mathrm{C}$; and no use of forced cooling. As the reference conditions were determined with recommend calibration protocols, with the exception of the envelope temperature (that is not included), it was also demonstrated the importance of following these protocols prior to printing with a new equipment or material. It was also shown that part critical dimensions should be defined in the printing plane, the most accurate one.

\section{References}

Ahn, S.H., Montero, M., Odell, D. and Wright, P.K. (2002), "Anisotropic material properties of fused deposition modeling ABS", Rapid Prototuping fournal, Vol. 8 No. 4, pp. 248-257.

Asgarpour, M., Bakir, F., Khelladi, S., Khavandi, A. and Tcharkhtchi, A. (2011), "Characterization and modeling of sintering of polymer particles", fournal of Applied Polvmer Science, Vol. 119 No. 5, pp. 2784-2792.

Bellehumeur, C., Bisaria, M. and Vlachopoulos, J. (1996), “An experimental study and model assessment of polymer sintering", Polvmer Engineering \& Science, Vol. 36 No. 17, pp. $2198-2207$.
Bellehumeur, C.T., Kontopoulou, M. and Vlachopoulos, J. (1998), "The role of viscoelasticity in polymer sintering", Rheologica Acta, Vol. 37 No. 3, pp. 270-278.

Bellehumeur, C., Li, L., Sun, Q. and Gu, P. (2004), "Modeling of bond formation between polymer filaments in the fused deposition modeling process", fournal of Manufacturing Processes, Vol. 6 No. 2, pp. 170-178.

Carneiro, O.S., Silva, A.F. and Gomes, R. (2015), "Fused deposition modeling with polypropylene", Materials $\mathcal{E}$ Design, Vol. 83, pp. 768-776.

Coasterman (2011), "The essential calibration set", available at: www.thingiverse.com/thing:5573 (accessed March 2018).

Costa, S.F., Duarte, F.M. and Covas, J.A. (2017), "Estimation of filament temperature and adhesion development in fused deposition techniques", Zournal of Materials Processing Technologv, Vol. 245, pp. 167-179.

Davis, C.S., Hillgartner, K.E., Han, S.H. and Seppala, J.E. (2017), "Mechanical strength of welding zones produced by polymer extrusion additive manufacturing", Additive Manufacturing, Vol. 16, pp. 162-166.

Górski, F., Wichniarek, R., Kuczko, W. and Abdrezejewski, J. (2015a), "Experimental determination of critical orientation of ABS parts manufactured using fused deposition modeling technology", fournal of Machining Engineering, Vol. 15, pp. 121-132.

Górski, F., Wichniarek, R., Kuczko, W., Zawadzki, P. and Buń, P. (2015b), "Strength of ABS parts produced by fused deposition modeling technology - a critical orientation problem", Advances in Science and Technology Research fournal, Vol. 9, pp. 12-19.

Gurrala, P.K. and Regalla, S.P. (2014), "Part strength evolution with bonding between filaments contributes to the strength of final FDM part", Virtual and Phusical Prototyping, Vol. 9 No. 3, pp. 141-149.

Hornsby, P. and Maxwell, A. (1992), "Mechanism of sintering between polypropylene beads", fournal of Materials Science, Vol. 27 No. 9, pp. 2525-2533.

Khaliq, M., Gomes, R., Fernandes, C., Nóbrega, J., Carneiro, O. and Ferrás, L. (2017), "On the use of high viscosity polymers in the fused filament fabrication process", $\underline{\text { Rapid }}$ Prototuping Fournal, Vol. 23 No. 4, pp. 727-735.

Lanzotti, A., Grasso, M., Staiano, G. and Martorelli, M. (2015), "The impact of process parameters on mechanical properties of parts fabricated in PLA with an open-source 3D printer", Rapid Prototuping fournal, Vol. 21 No. 5, pp. 604-617.

Lee, B., Abdullah, J. and Khan, Z. (2005), "Optimization of rapid prototyping parameters for production of flexible ABS object", Zournal of Materials Processing Technologv, Vol. 169 No. 1, pp. 54-61.

Li, L., Sun, Q., Bellehumeur, C. and Gu, P. (2002), "Investigation of bond formation in FDM process", Solid Freeform Fabrication Symposium, Austin, TX.

Pollard, D., Ward, C., Herrmann, G. and Etches, J. (2017), "Filament temperature dynamics in fused deposition modelling and outlook for control", Procedia Manufacturing, Vol. 11, pp. 536-544.

Seppala, J.E., Han, S.H., Hillgartner, K.E., Davis, C.S. and Migler, K.B. (2017), "Weld formation during material 
extrusion additive manufacturing", Soft Matter, Vol. 13, pp. 6761-6769.

Shaffer, S., Yang, K., Vargas, J., Di Prima, M.A. and Voit, W. (2014), "On reducing anisotropy in $3 \mathrm{~d}$ printed polymers via ionizing radiation", Polvmer, Vol. 55 No. 23, pp. 5969-5979.

Spoerk, M., Arbeiter, F., Cajner, H., Sapkota, J. and Holzer, C. (2017), "Parametric optimization of intra- and inter-layer strengths in parts produced by extrusion-based additive manufacturing of poly(lactic acid)", fournal of Applied Polymer Science, doi: 10.1002/APP.45401.

Sun, Q., Rizvi, G.M., Bellehumeur, C.T. and Gu, P. (2003), "Experimental study of the cooling characteristics of polymer filaments in FDM and impact on the mesostructures and properties of prototypes", Solid Freeform Fabrication Symposium, Austin, TX.

Sun, Q., Rizvi, G., Bellehumeur, C. and Gu, P. (2008), "Effect of processing conditions on the bonding quality of FDM polymer filaments", Rapid Prototyping foumal, Vol. 14 No. 2, pp. 72-80.

Thomas, J. and Rodríguez, J. (2000), "Modeling the fracture strength between fused deposition extruded roads", Solid Freeform Fabrication Symposium, Austin, TX.

Umetani, N. and Schmidt, R. (2013), "Cross-sectional structural analysis for 3D printing optimization", SIGGRAPH Asia Technical Briefs, Hong Kong.
Wu, W., Geng, P., Li, G., Zhao, D., Zhang, H. and Zhao, J. (2015), "Influence of layer thickness and raster angle on the mechanical properties of 3D-printed PEEK and a comparative mechanical study between PEEK and ABS", Materials, Vol. 8 No. 9, pp. 5834-5846.

Yardimci, M. and Güçeri, S. (1996), "Conceptual framework for the thermal process modelling fused deposition", $\underline{\text { Rapid }}$ Prototvping fournal, Vol. 2, pp. 23-31.

Zhang, J., Wang, X.Z., Yu, W.W. and Deng, Y.H. (2017), "Numerical investigation of the influence of process conditions on the temperature variation in fused deposition modeling", Materials \& Design, Vol. 130, pp. 59-68.

\section{Further reading}

Turner, B.N., Strong, R. and Gold, S.A. (2014), “A review of melt extrusion additive manufacturing processes: I: process design and modeling", Rapid Prototyping fournal, Vol. 20 No. 3, pp. 192-204.

\section{Corresponding author}

Olga Sousa Carneiro can be contacted at: olgasc@dep. uminho.pt 
This article has been cited by:

1. Amy M. Peterson. 2019. Review of acrylonitrile butadiene styrene in fused filament fabrication: A plastics engineering-focused perspective. Additive Manufacturing 27, 363-371. [Crossref] 